Research Article

\title{
Development of Bed Linen Performance Index
}

\author{
Messay Dubale $\mathbb{D},{ }^{1}$ Hermela Ejegu $\mathbb{D},{ }^{2}$ Wondwossen Mamuye $\mathbb{D},{ }^{1}$ and Solomon Addis $\mathbb{D}^{1}$ \\ ${ }^{1}$ Ethiopian Textile Industry Development Institute (ETIDI), Addis Ababa, Ethiopia \\ ${ }^{2}$ Department of Textile Engineering, Dire Dawa University Institute of Technology, Dire Dawa, Ethiopia
}

Correspondence should be addressed to Messay Dubale; mesaydubale@gmail.com

Received 6 June 2021; Accepted 20 September 2021; Published 29 September 2021

Academic Editor: Abdullah A. Kendoush

Copyright ( 2021 Messay Dubale et al. This is an open access article distributed under the Creative Commons Attribution License, which permits unrestricted use, distribution, and reproduction in any medium, provided the original work is properly cited.

In order to develop the performance of the bed linen index objectively, the first seven properties of the fabric are selected by twenty-four experts subjectively, and these experts also give the weight for each property according to the necessity. These properties are total hand value (THV), moisture management, abrasion resistance, air permeability, wrinkle recovery, thermal resistance, and drape of fabric. After selecting the properties and the weight for each characteristic, an integrated index for bed linen performance value is developed. Before directly using the value of each property into the equation, normalization of data should be done to shrink the range of the data such that the range is fixed between 1 and 5 . The correlation between subjective and objective evaluations was very high $(r=0.82)$. This indicates that the bed linen performance index could be estimated as well.

\section{Introduction}

Today buyers and consumers are much more comfortand performance-conscious than ever before. Bed linen is a sheet of material used to cover the bed, which should be soft with a warm handle and easy-care properties. Depending on the end-use, cost factor, durability of the textiles, comfort, and aesthetic properties, the fiber choice is made from natural fiber, regenerated cellulosic fibers, and synthetic fibers [1]. The comfort of sleeping is a vital component of daily life, and its level depends on the design of the bed climate condition in the bedroom and thermo physiological and thermal contact property of cushions and bed sheets $[2,3]$. The major requirement of a fabric sheet is to be comfortable, nice to touch and durable to wear, and easy care $[1,4]$. The bed linen performance index is used to give an overall performance value for bed linen. The performance of bed linen can be judged by sleeping quality. This sleep quality has four basic factors. These are health conditions, emotional status, bedding conditions, and thermal environment [5]. So, the engineering of appropriate bed linen may influence sleep quality because of this there is a need to develop some performance index using the basics of textile science, which is developed based on a survey which is conducted to decide the contribution of different characteristics of bed linen. To develop a universally accepted standard to evaluate the performance of bed linen fabric using an objective measurement of fabric quality parameters, first select the appropriate parameter about bed linen performance index and then ask the textile experts about which properties are necessary for bed linen performance and which fabric properties has the highest weightage when they are compared to each other. Among various properties, hand value, air permeability, moisture management, thermal insulation, drape, abrasion resistance, and crease recovery have become the primary consideration in determining the performance of bed linen.

After subjective assessment of the abovementioned properties, they are evaluated according to their appropriate methods, and then the data will be normalized to develop the index [6]. Normalization transforms heterogeneous criteria data (qualitative, quantitative, different units, etc.) into numerical and comparable data to enable aggregation (fusion) of criteria to determine the rating of decision alternatives $[7,8]$. The abovementioned characteristic has different units, so one of the first steps concerns the normalization of the data. This step is very important when dealing with parameters of different units and scales $[7,9]$. 


\section{Materials and Methodology}

2.1. Materials. A wide range of bed sheet sample fabrics is produced under industrial manufacturing condition. The sample is developed by selecting different types of natural and man-made fibers and their blends which are cotton, viscose, modal, excel, polyester, modal/cotton, and cotton/ viscous (Table 1).

2.2. Methodology. To develop the bed linen performance index, the following steps needed to be followed. These steps are subjective assessment on bed linen performance properties, evaluation of fabric properties, normalization of each property of the fabric, and calculation of the bed linen performance index.

2.2.1. Subjective Assessment on Bed Linen Performance Properties. To develop the equation for the performance of bed linen fabric using an objective measurement based on the fabric quality parameters, first select the appropriate parameter about BLPI and ask the experts about which properties are necessary for bed linen performance and which properties have the highest importance among the selected properties. Based on the selected parameters, the fabric evaluation will be followed.

2.2.2. Evaluating the Property of Fabrics. Seven important properties are important for the bed linen fabric. These properties are fabric hand, air permeability, moisture management, thermal resistance, abrasion resistance, and fabric drape and crease recovery.

(1) Fabric Hand. The Kawabata evaluation system (KES) instruments measure sixteen low-stress mechanical properties of the fabric which help us to calculate the primary and total hand value of fabrics. In KES instruments, there are four different types of testing instrument which measure tensile and shear (as shown Figure 1) and bending, compression, and surface properties of fabrics (as shown as Figures 2 and 3 ).

(2) Moisture Management. The moisture management properties of the fabric are measured by a moisture management tester. This testing machine measures and classifies liquid management property fabrics. To measure the dynamic liquid transport properties of a fabric, a sample is placed horizontally in the instrument between the upper and lower electrical sensors. These sensors are made of concentric rings of pins, a test solution is moving in a different direction such as radial spreading on the top surface, movement through the specimen from a top surface to bottom surface, and radial spreading on the bottom surface. In place of perspiration, the solution is released on the center of upper side of the fabric. As the liquid passes through and across the sample, the difference in the electrical resistance is measured and recorded.
(3) Thermal Resistance. The thermal resistance of bed sheet fabric samples is measured by the KES-F7 Thermolabo tester as shown in Figure 4. This tester measures thermal resistance. To measure the thermal resistance of fabric, first, the sample is set on a heat plate with a constant temperature (at room temperature $+10^{\circ} \mathrm{C}$ ) and is left in contact with the air. The amount of heat lost through the sample is then measured to calculate the thermal resistance of the fabric.

(4) Air Permeability. The air permeability of fabric is defined as the rate of airflow passing perpendicular through an identified area under a given air pressure difference between two surfaces, and it measures the pressure drop through the fabric as indicated in Figure 5. The sample is held between two rubber gaskets and a guarded ring over the air inlet to make sure that the airflow passes through the sample with linkage. Then, the air is drawn through the sample using suction. At this point, it measured the rate of airflow by using a flow meter. The air permeability value of the fabric is different across the whole area of a sample because of irregularity in the yarn.

(5) Drape. In the drape test, the sample is deformed with three-dimensional curvature and so the outcomes are depending on a certain amount of the shear properties of the fabric. The results are mostly dependent on the bending stiffness of the fabric.

In this experiment, a circular specimen is held in the center between two less diameter horizontal discs and is allows to drape and fold under its weight. A light is shown from the bottom of the sample and the shadow that came from the sample is traced onto an annular piece of paper the same size as the unsupported part of the fabric specimen as shown in Figure 6.

To know the areas involved during the drape, the total paper ring is measured and then the shadow part of the ring is cut away and weighed. The paper is assumed to have a constant mass per unit area so that the measured mass is proportional to the area. The drape coefficient can then be calculated using the following equation.

$$
\text { Drape coefficient }=\frac{(\text { mass of the shaded area })}{(\text { total mass of the paper })} * 100 \text {. }
$$

(6) Abrasion Resistance. Abrasion is a part of wear, and it rubs away the surface of fibers and yarns of the fabric. Inherent fiber such as work of rupture may give a high resistance to abrasion. The abrasion resistance of the fabric is tested in the Martindale abrasion tester as shown in Figure 7. The advantage of the Martindale abrasion test is that the fabric sample gets abrasion in all directions. In the Martindale abrasion resistance tester, $38 \mathrm{~mm}$ diameter circular specimens are abraded under known pressure against a standard fabric. The pressure used for this test is $9 \mathrm{kPa}$ for all samples. During testing, 10,000 cycles were used for all samples. After completing the abrasion, the weight loss of the fabric will be calculated. 
TABLE 1: Fabric samples and their specification.

\begin{tabular}{|c|c|c|c|c|c|}
\hline Fiber mix & Warp count $(\mathrm{Ne})$ & Weft count $(\mathrm{Ne})$ & GSM & Weave & EPI*PPI \\
\hline $100 \%$ cotton & $28 \mathrm{~s}$ & $28 \mathrm{~s}$ & 120 & Plain & $80 * 65$ \\
\hline $100 \% \mathrm{PET}$ & $64 \mathrm{~s}$ & $15 \mathrm{~s}$ & 96 & Plain & $84^{*} 42$ \\
\hline $100 \%$ excel & $60 / 1$ & $80 / 1$ & 142 & 5 end satin & $192 * 70 * 3$ \\
\hline $100 \%$ modal & $60 s$ & $60 \mathrm{~s}$ & 125 & Satin & $188^{*} 60 / 2$ \\
\hline $70: 30 \mathrm{modal} / \mathrm{cotton}$ & $60 s$ & $60 \mathrm{~s}$ & 125 & Satin & $192 * 62 / 2$ \\
\hline $55: 45$ cotton/viscose & $\begin{array}{c}40 \mathrm{~s} \\
\text { viscose }\end{array}$ & $\begin{array}{c}30 \mathrm{~s} \\
\text { cotton }\end{array}$ & 107 & $2 / 1$ twill & $82 * 70$ \\
\hline
\end{tabular}

$\mathrm{PET}=$ polyester, $\mathrm{Ne}=$ English count, $\mathrm{GSM}=$ mass per unit Area, $\mathrm{EPI}=$ Ends per inch $\mathrm{PPI}=$ Picks per inch .

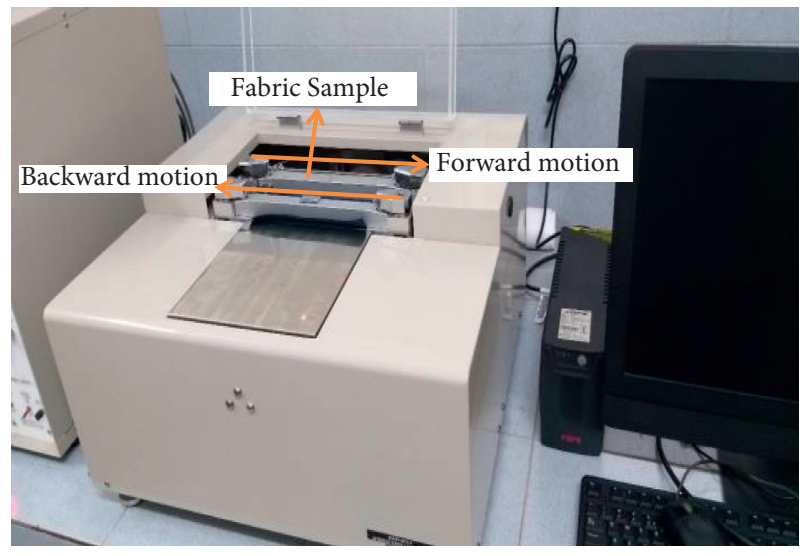

FIGURE 1: KES-FB1: tensile and shear tester analyses of hand movements.

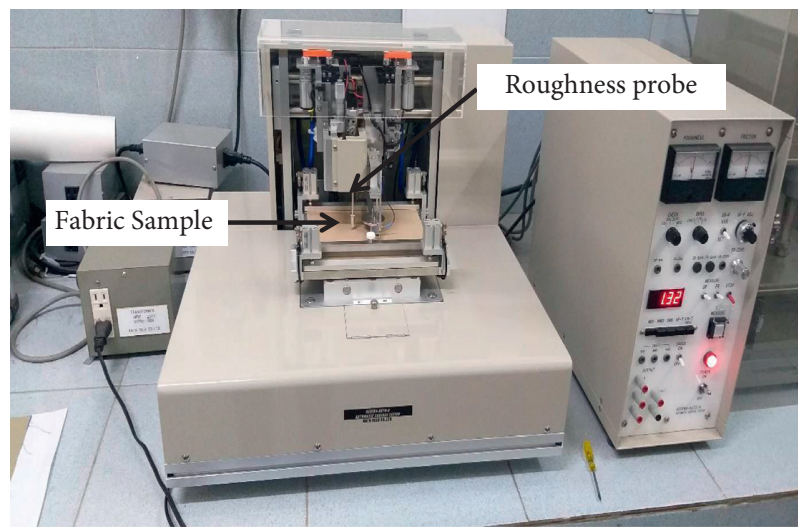

Figure 2: KES-FB4: surface test analyses of hand movement.

(7) Crease Recovery. Crease recovery is measured quantitatively in terms of crease recovery angle. Crease recovery is a property of a fabric that shows the ability of a sample to return its original position after creasing. To measure this, the Shirley crease recovery tester is most popular.

The samples are cut from the fabric with a temple, 2 inches long by one inch wide in warp and weft side. The Shirley crease recovery instrument consists of a circular dial that has a clamp for holding the sample. From the center of the dial, there is a knife-edge for measuring the recovery angle. Crease recovery of sample is depending upon the recovery angle. When the angle of recovery is $0^{\circ}$ which means the fabric, recovery is zero, and when the angle

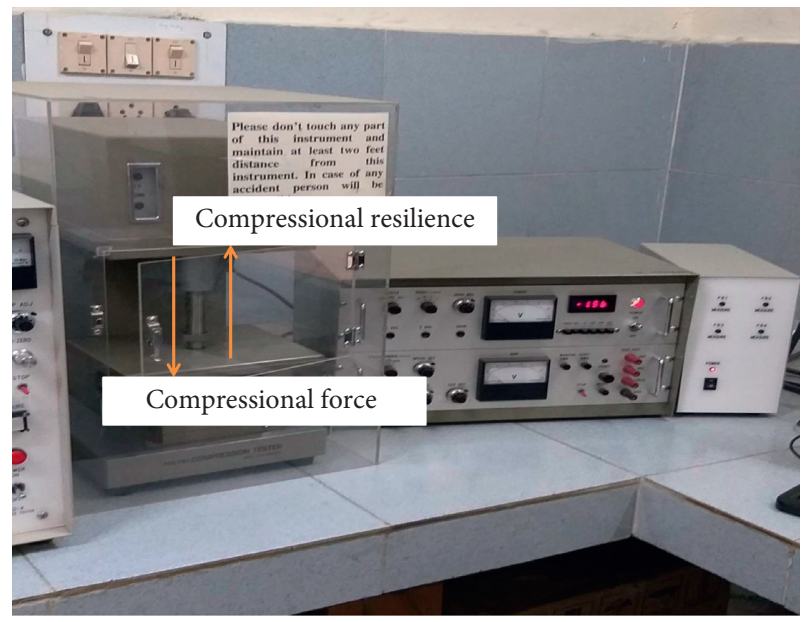

FIgURE 3: KES-FB3: compression tester analyses of hand movement.

becomes $180^{\circ}$, which means its recovery is full. Here, the recovery angle for the given fabric sample in the middle of the range. So, it is to say that the crease recovery of the sample fabric is average.

\section{Results and Discussion}

3.1. Development of Bed Linen Performance Index (BLPI). The subjective assessment was used to develop the weight of each attribute, an expert panel is constituted, and a survey was conducted to decide the contribution of each of the above seven characteristics of the fabric. The weight for different characteristics required for BLPI is calculated by 24 experts which is a subjective method. Subsequently, a discriminant analysis was carried out to examine the agreement among the judges' opinions.

The experts give their rank for each property to show which properties can conclude in the bed linen performance index and which properties come first. Based on this subjective assessment, total hand value got the first rank and moisture management, abrasion Resistance, air permeability, crease recovery, thermal resistance, and drape have second up to the seventh rank, respectively.

To identify the weight contribution of fabric properties, the experts are giving their percent to each property from 0 up to $100 \%$ According to the expert survey on bed linen performance index, a total hand value of fabric has a higher weight than another fabric property. It means $29 \%$ of the 


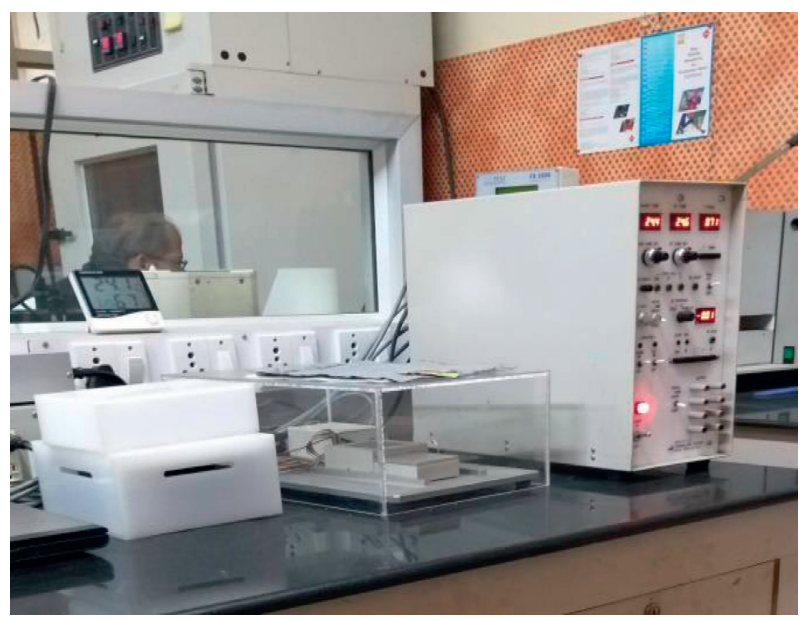

FIGURE 4: KES-F7 Thermolabo tester for testing thermal resistance.

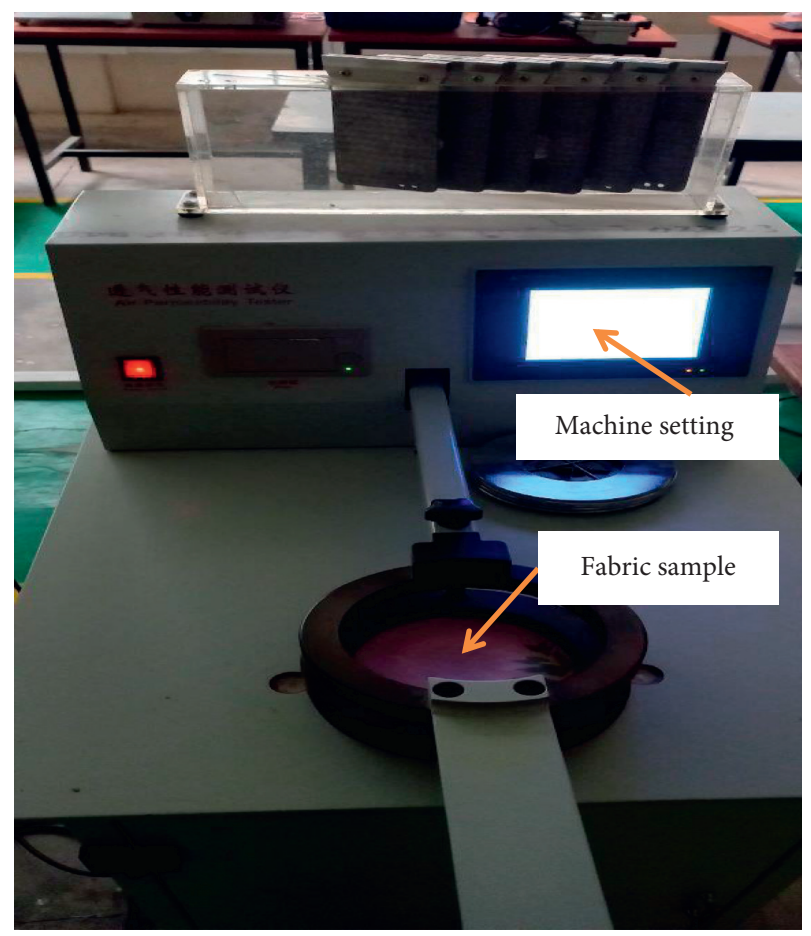

FIGURE 5: Air permeability testing machine.

weight is taken by THV, and the moisture management, thermal resistance, abrasion resistance, air permeability, drape, and crease recovery have $15,13,14,12,6$ and 11 respectively. The weight decided by experts is given in Table 2.

3.2. Properties of Bed Linen Fabrics. Each of these properties was evaluated from a different testing machine. They are integrated to find the bed linen performance index. The results are shown in Table 3.

(1) Bed Linen Performance Index. The seven major properties which are identified to have a direct influence on the performance of bed linen are total hand value, moisture

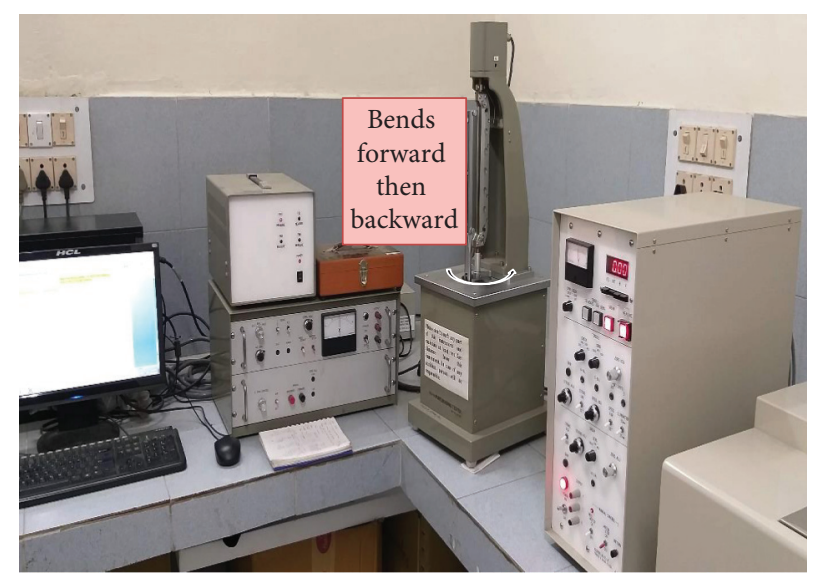

FIGURE 6: KES-FB2: a pure bending tester analyses.

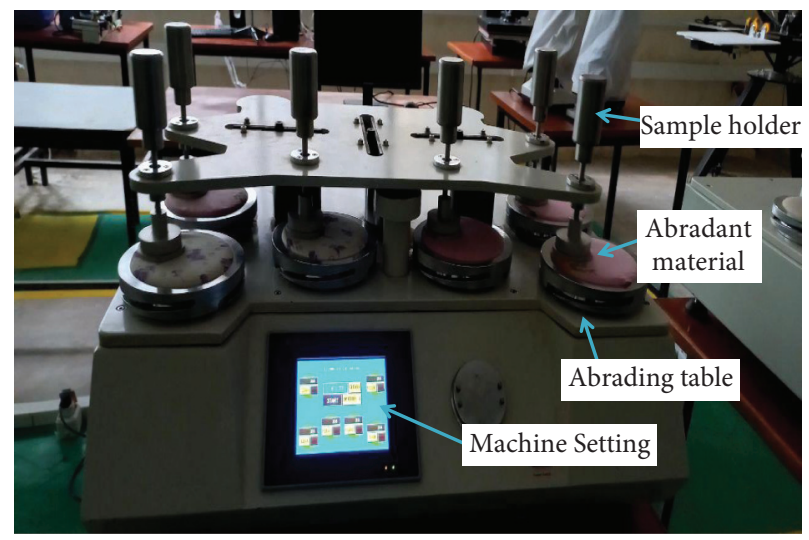

Figure 7: Martindale abrasion tester machine.

management, abrasion resistance, air permeability, crease recovery, thermal resistance, and drape. Each of these properties was evaluated from a different testing machine. They are integrated to find the bed linen performance index. The results are shown in Table 3. Finally, with the help of the above weightage, an integrated index for performance value was determined using the formula:

$$
\mathbf{B L P I}=\sum_{i=1}^{n} A_{i} * W_{i},
$$

where: $n=$ total number of properties. $A_{\mathrm{i}}=$ index of the $i^{\text {th }}$ property. $W_{\mathrm{i}}=$ weightage of the $i^{\text {th }}$ property.

To develop the index, the above data (Table 3) should be normalized. When you normalize data, you eliminate the units of measurement for data, enabling you to more easily compare data from different places. So, to normalize the seven characteristics by shrinking the data in the range between 1 and 5, every characteristic result comes between these ranges. This helps to compare the subjective assessment of bed linen (Table 4) scaled characteristics value (with 1-5 range) performance with the objective measured bed linen performance index. The maximum value is 5 which indicates the fabric has a higher bed linen performance index, and the minimum value is 1 which indicates a lower 
TABLE 2: Weight contribution of subjective assessment.

\begin{tabular}{lccc}
\hline Property & Rank & Actual weightage (\%) & Approximate weightage (\%) \\
\hline Total hand value & 1 & 28.70 & 29 \\
Moisture management & 2 & 15.43 & 15 \\
Abrasion resistance & 3 & 13.83 & 14 \\
Air permeability & 4 & 12.17 & 12 \\
Crease recovery & 5 & 10.96 & 11 \\
Thermal resistance & 6 & 12.61 & 13 \\
Drape & 7 & 6.30 & 6 \\
\hline
\end{tabular}

TABLe 3: Total evaluated properties of bed linen.

\begin{tabular}{lccccccc}
\hline $\begin{array}{l}\text { Fiber } \\
\text { mix }\end{array}$ & THV & $\begin{array}{c}\text { MMT } \\
(\%)\end{array}$ & $\begin{array}{c}\text { Abrasion resistance } \\
(\text { weight loss } \%)\end{array}$ & $\begin{array}{c}\text { Air permeability } \\
\left(\mathrm{cm}^{3} / \mathrm{cm}^{2 *}\right)\end{array}$ & $\begin{array}{c}\text { Crease recovery } \\
(\text { degree })\end{array}$ & $\begin{array}{c}\text { Thermal resistance } \\
\left(\mathrm{M}^{2 \circ} \mathrm{C} / \mathrm{W}\right)\end{array}$ & $\begin{array}{c}\text { Drape } \\
\text { coefficient }(\%)\end{array}$ \\
\hline Cotton & 2.124 & 985.69 & 4.54 & 41.4 & 83.7 & 0.132 & 4 \\
PET & 0.075 & 1060.46 & 11.6 & 30.084 & 127 & 0.143192 & 9.8 \\
Excel & 1.232 & 214.57 & 7.73 & 30.05 & 90.25 & 0.132895 & 6.4 \\
Modal & 2.316 & 662.3 & 5.22 & 50.125 & 89.5 & 0.133784 & 31 \\
M/C & 3.930 & 703.1 & 4.05 & 11 & 92.5 & 0.130837 \\
C/V & 1.98 & 960 & 8.8 & 96.8 & 72.5 & 0.136073 & 3.69 \\
\hline
\end{tabular}

TABle 4: Scaled characteristics value (with 1-5 range).

\begin{tabular}{|c|c|c|c|c|c|c|c|c|}
\hline Fiber mix & THV & MMT & Abrasion resistance & Air permeability & Crease recovery & Thermal resistance & Drape coefficient & BLPI \\
\hline Cotton & 3.20 & 4.65 & 4.74 & 2.42 & 1.82 & 1.38 & 1.05 & 3.02 \\
\hline PET & 1.00 & 5.00 & 1.00 & 1.89 & 5.00 & 5.00 & 1.89 & 2.72 \\
\hline Excel & 2.31 & 1.00 & 3.05 & 1.89 & 2.30 & 1.67 & 1.40 & 2.02 \\
\hline Modal & 3.39 & 3.12 & 4.38 & 2.82 & 2.25 & 1.95 & 5.00 & 3.21 \\
\hline $\mathrm{M} / \mathrm{C}$ & 5.00 & 3.31 & 5.00 & 1.00 & 2.47 & 1.00 & 4.41 & 3.43 \\
\hline $\mathrm{C} / \mathrm{V}$ & 3.06 & 4.52 & 2.48 & 5.00 & 1.00 & 2.70 & 1.00 & 3.04 \\
\hline
\end{tabular}

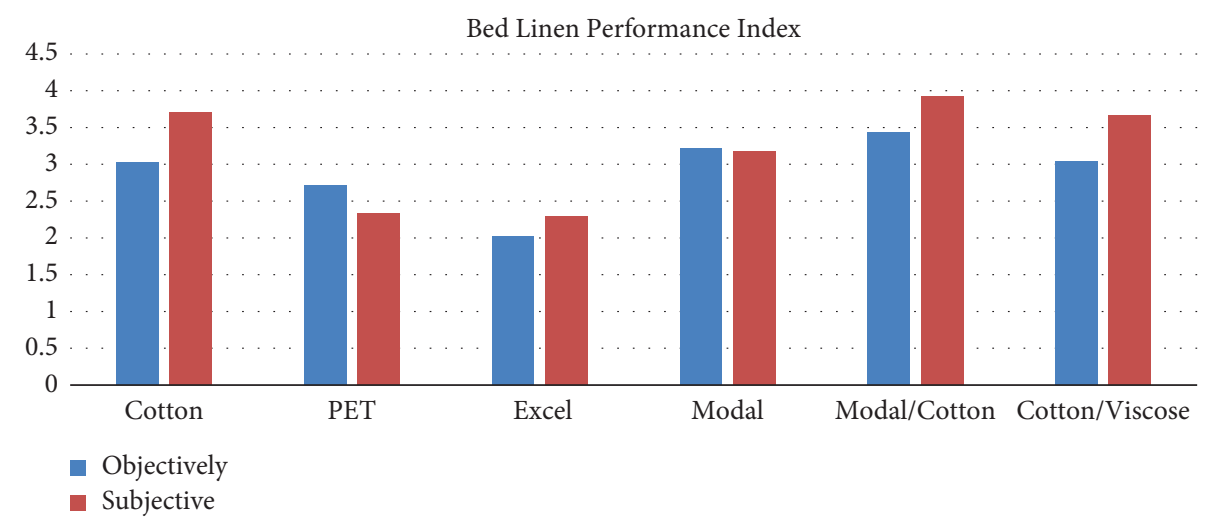

FIGURE 8: Normalized bed linen performance index.

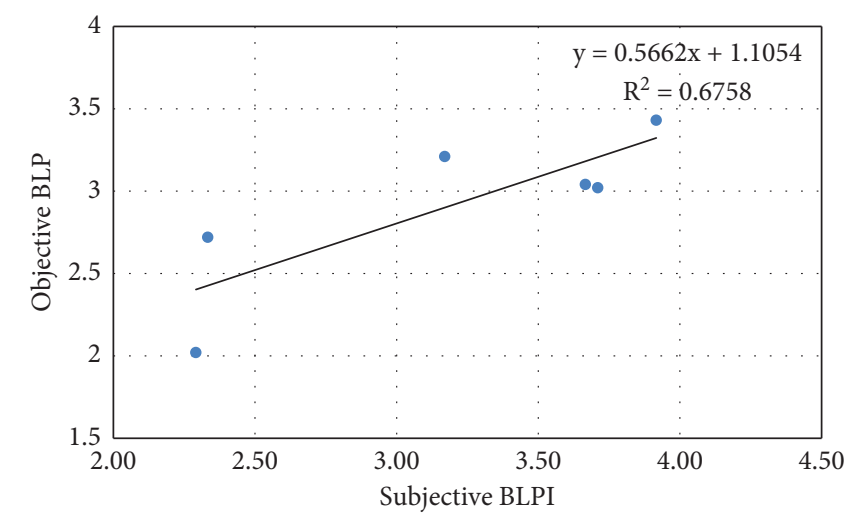

FIGURE 9: Correlation between subjective and objective bed linen performance. 
bed linen performance index. The results are shown in Figures 8 and 9 and tabulated in Table 4 .

$$
\begin{aligned}
\text { Scaled properties }= & \frac{\mathrm{X}_{\mathrm{i}}-\min _{\mathrm{i}}}{\max _{\mathrm{i}}-\min _{\mathrm{i}}} *(\text { max range }- \text { min range }) \\
& + \text { min range }
\end{aligned}
$$

where $i=$ properties. $X_{i}=$ value of properties. Mini$=$ minimum value of properties. Maxi $=$ maximum value of properties. Max range $=$ maximum value is 5 . Min range $=$ minimum value is 1 .

\section{Conclusion}

During the development of the bed linen performance index, there are seven properties of fabrics, which are total hand value, moisture management, abrasion resistance, air permeability, crease recovery, thermal resistance, and drape. These seven properties have weightage, with the help of this weightage; an integrated index for bed linen performance value is developed. Modal-cotton blend fabric shows the highest bed linen performance than the other fabrics. These fabrics have the highest total hand value, abrasion resistance, crease recovery, and drape coefficient. 100\% excel fiber has the very lowest performance index, and this fabric has the very lowest BLPI value as it has the lowest moisture management, drape coefficient, and air permeability because the excel fabric has higher thickness than the other fabric. The correlation between subjective and objective evaluations was very high $(R=0.82)$. This indicates that the bed linen performance index could be estimated as well.

\section{Data Availability}

The data supporting the findings of this study are all presented within the article.

\section{Conflicts of Interest}

The authors declare no conflicts of interest.

\section{References}

[1] S. Sundaresan, M. Ramesh, V. Sabitha, M. Ramesh, and V. Ramesh, "A detailed analysis on physical and comfort properties of bed linen woven fabrics," International Journal of Advanced Research and Innovative Ideas in Education, vol. 2, no. 2, pp. 1649-1658, 2016.

[2] L. Hes, M. Bogusławska-Baczek, and M. J. Geraldes, "Thermal comfort of bed sheets under real conditions of use," Journal of Natural Fibers, vol. 11, no. 4, pp. 312-321, 2014.

[3] A. Basit, W. Latif, S. A. Baig, A. Rehman, M. Hashim, and M. Zia, "The mechanical and comfort properties of viscose with cotton and regenerated fibers blended woven fabrics," Material science, vol. 24, no. 2, pp. 1392-1320, 2018.

[4] S. S. Lavate, M. C. Burji, and S. Patil, "Study of yarn and fabric properties produced from modified viscose tencel, excel, modal and their comparison against cotton," 2016.
[5] L. Lan and Z. Lian, "Ten questions concerning thermal environment and sleep quality," Building and Environment, vol. 99, pp. 252-259, 2016.

[6] T. Ogulat, "Air permeability of woven fabrics," Journal of Textile and apparal, technology and management, vol. 5, no. 2, 2006.

[7] C. Saranya and G. Manikandan, "A study on normalization techniques for privacy preserving data mining," International Journal of Engineering and Technology, vol. 5, no. 3, pp. 0975-4024, 2013.

[8] W. Latif, A. Basit, Z. Ali, and S. A. Baig, "The mechanical and comfort properties of cotton and regenerated fibers blended woven fabrics," Journal of Natural Fibers, vol. 24, no. 2, pp. 836-845, 2018.

[9] E. Carrera-Gallissà, X. Capdevila, and J. Valldeperas, "Correlation analysis between the kawabata system (KES-F) and the UPC ring methods of fabric analysis," Journal of Engineered Fibres and Fabrics, vol. 11, no. 2, 2016. 